\title{
Autoantibody Profile of Egyptian Juvenile Systemic Lupus Erythematosus Patients and Its Association with Clinical Characteristics and Disease Activity
}

Mohammed Abd El Monem Teama (iD) ${ }^{\prime}$ Marwa Adham El-Mohamdy ${ }^{2}$ Fatma Abdellah Abdullah Mahmoud ${ }^{2}$ Fatma Mohammed Badr

'Internal Medicine Department, Division of Rheumatology and Immunology, Faculty of Medicine, Ain Shams University, Cairo, Egypt; ${ }^{2}$ Clinical Pathology Department, Faculty of medicine, Ain Shams University, Cairo, Egypt
Correspondence: Mohammed Abd El Monem Teama 2 Staff Member Buildings of Ain Shams University, El Al Waili/ElAbaseya, Cairo, II517, Egypt Tel +201277580006

Email mohteama2009@yahoo.com
Objective: This study was conducted to estimate the frequency of anti-nuclear antibodies (ANAs), anti-dsDNA, and anti-extractable nuclear antigen (ENA) antibodies in juvenile systemic lupus erythematosus (JSLE) patients and their association with different clinical manifestations and disease activity.

Patients and Methods: A cross-sectional study that includes 100 JSLE patients from Ain Shams University Hospital was conducted. All subjects underwent history taking, clinical examination, assessment of disease activity based on the SLE disease activity index (SLEDAI), laboratory investigations, and tests for autoantibodies, namely ANA, antidsDNA, and anti-ENA antibodies, including anti-Ro (SSA), anti-La (SSB), anti-Smith (Sm), and anti-U1-ribonucleoprotein (U1-RNP).

Results: The most common clinical features were polyarthralgia (71\%), haematological manifestations (65\%), malar rash (54\%), and nephritis (51\%), respectively. All patients had positive ANA (100\%), while anti-dsDNA frequency was $83 \%$. The most common anti-ENA antibodies were anti-RNP (41\%), anti-Sm (31\%), anti-SSA (27\%), and anti-SSB (20\%), respectively. Anti-RNP had a clinical association with oral ulcer, Raynaud' phenomena, haematological, neuropsychiatric and thromboembolic manifestations. Meanwhile, anti-Sm had a significant association with serositis, mucocutaneous, constitutional, and neuropsychiatric manifestations. Anti-SSA was associated with mucocutaneous, musculoskeletal, Raynaud' phenomena, renal, haematological and cardiac manifestations, while anti-SSB was significantly associated with malar rash, serositis, thromboembolic, musculoskeletal, and neuropsychiatric manifestations. Concerning SLEADI score, anti-dsDNA antibody was significantly associated with moderate disease activity score $(p=0.032)$ while anti-SSA significantly associated with high disease activity $(\mathrm{p}=0.045)$. Both anti-SSB and anti-Sm were significantly associated with both moderate and high disease activities, meanwhile antiU1-RNP was associated with moderate disease activity $(\mathrm{p}=0.014)$.

Conclusion: Anti-dsDNA and anti-ENAs antibodies were frequently found in JSLE patients $(83 \%, 63 \%)$, respectively. They were significantly associated with variable clinical manifestations and could be used as predictors for assessment of disease activity.

Keywords: juvenile systemic lupus erythematosus, clinical manifestations, anti-ENA, disease activity score

\section{Introduction}

Systemic lupus erythematosus (SLE) is a chronic autoimmune disorder that is most common among the young-aged females. Its exact cause is still unclear; however, it 
Table I Demographic Data of JSLE Patients Included in This Study $(n=100)$

\begin{tabular}{|c|c|}
\hline Demographic Data & Total $(n=100)$ \\
\hline \multicolumn{2}{|l|}{ Age (years) } \\
\hline Range & $9-16$ \\
\hline Mean \pm SD & $12.91 \pm 1.94$ \\
\hline \multicolumn{2}{|l|}{ Sex } \\
\hline Female & 97 (97.0\%) \\
\hline Male & $3(3.0 \%)$ \\
\hline \multicolumn{2}{|c|}{ Disease duration (years) } \\
\hline Range & $1-10.83$ \\
\hline Mean $\pm S D$ & $3.57 \pm 2.66$ \\
\hline
\end{tabular}

may be a result of the interplay between many genetic, epigenetic, and environmental factors. ${ }^{1}$

Juvenile SLE (JSLE) is that type of SLE that affects people $<18$ years old. Worldwide, it is estimated to be 10 $20 \%$ of all SLE cases. ${ }^{2}$ Moreover, the introductory disease severity of JSLE is much greater than adult type. Flares and new systems/organs involvement may develop after a longterm remission, up to 10 years after the initial diagnosis. ${ }^{3}$

The hallmark of SLE is the excessive production of pathogenic antibodies recognizing self-antigens and the formation of antigen-antibody complexes that trigger the immune response to cause multiple organ injury. ${ }^{4}$ This includes antinuclear antibodies (ANAs) which are found in almost all patients with SLE, double-stranded DNA (dsDNA), and a variety of anti-extractable nuclear antigen (ENA) antibodies are detected in SLE patients at diagnosis and during disease progression. ${ }^{5}$ These antibodies include four groups of RNA-binding proteins, namely Sm, RNP, SSA and SSB. ${ }^{6}$

Owing to the pathophysiological significance of autoantibodies in SLE, several studies have attempted to elucidate the association between anti-ENA antibodies and SLE specific clinical features. Anti-ds DNA antibodies and anti-Sm antibodies are highly specific for SLE, and the presence of anti-dsDNA and/or anti-Sm antibodies is one of the important criteria for the classification of SLE. ${ }^{7,8}$

Anti-dsDNA antibody titer has been reported to be consistently associated with the development of lupus nephritis and disease flare in patients with SLE. ${ }^{9,10}$ However, the clinical significance of anti-ENA antibodies remains unclear, but it may predict the involvement of different organs as well as the severity of the disease,
Table 2 Distribution of Different Clinical, Laboratory Data and SLEDAI Score Among JSLE Patients $(n=100)$

\begin{tabular}{|c|c|}
\hline Cumulative Clinical Data & $\begin{array}{c}\text { Number } \\
\text { (\%) }\end{array}$ \\
\hline Malar rash & $54(54.0)$ \\
\hline Oral ulcer & $33(33.0)$ \\
\hline Polyarthralagia & 7I (7I.0) \\
\hline Photosensitivity & $47(47.0)$ \\
\hline Alopecia & $29(29.0)$ \\
\hline Constitutional symptoms(fever, fatigue) & $10(10.0)$ \\
\hline Nephritis & $5 I(5 I)$ \\
\hline Hematological manifestations & $65(65)$ \\
\hline Leukopenia $\left(<4 \times 10^{9} / \mathrm{L}\right)$ & $30(30.0)$ \\
\hline Neutropenia & $30(30.0)$ \\
\hline Lymphopenia & $35(35.0)$ \\
\hline Anemia $(<12 \mathrm{~g} / \mathrm{dl})$ & $53(53.0)$ \\
\hline Autoimmune hemolytic anemia (AIHA) & $19(19.0)$ \\
\hline Thrombocytopenia $\left(<150 \times 10^{9} / \mathrm{L}\right)$ & $40(40.0)$ \\
\hline Serositis & $12(12.0)$ \\
\hline Pleural effusion & $3(3.0)$ \\
\hline Pericardial effusion & $9(9.0)$ \\
\hline Neuropsychiatric manifestations & $27(27)$ \\
\hline Seizures & $8(8.0)$ \\
\hline Hemiparesis & $3(3)$ \\
\hline Peripheral neuropathy & $2(2)$ \\
\hline Psychosis (excluding corticosteroid psychosis) & $14(14.0)$ \\
\hline Thromboembolic Event & $23(23)$ \\
\hline Arterial thrombosis & $7(7.0)$ \\
\hline Venous thrombosis & I5 (I5.0) \\
\hline Recurrent thrombosis & I (I.0) \\
\hline Cardiac involvement & $26(26.0)$ \\
\hline Heart failure (myocarditis) & $3(3.0)$ \\
\hline Valvular affection (endocarditis) & $21(21.0)$ \\
\hline Pericardial effusion & $9(9.0)$ \\
\hline Raynaud's phenomena & $8(8.0)$ \\
\hline Antiphospholipid syndrome & $18(18.0)$ \\
\hline \multicolumn{2}{|l|}{ Laboratory Data } \\
\hline $\begin{array}{l}\text { Creatinine: Increase }(>1.2 \mathrm{mg} / \mathrm{dl}) \\
\text { Creatinine clearance: Decrease }(\mathrm{mL} / \mathrm{min}) \\
(<90 \mathrm{~mL} / \mathrm{min})\end{array}$ & $\begin{array}{c}5(5.0) \\
37(37.0)\end{array}$ \\
\hline \multicolumn{2}{|l|}{ Hypocomplementemia } \\
\hline C3: Consumed (mg/dl) & $60(60.0)$ \\
\hline C4: Consumed (mg/dl) & $35(35.0)$ \\
\hline ESR: High ESR (>20 $\mathrm{mm} / \mathrm{hr})$ & $74(74.0)$ \\
\hline CRP: High CRP(>6 mg/dl) & II (II.0) \\
\hline \multicolumn{2}{|l|}{ Urine analysis } \\
\hline Pus cell & $30(30.0)$ \\
\hline Red Cell & $28(28.0)$ \\
\hline Albuminuria & $31(31.0)$ \\
\hline Urinary casts & $15(15.0)$ \\
\hline
\end{tabular}

(Continued) 
Table 2 (Continued).

\begin{tabular}{|l|c|}
\hline Cumulative Clinical Data & $\begin{array}{c}\text { Number } \\
\text { (\%) }\end{array}$ \\
\hline Protein/creatinine ratio: Abnormal (>0.2 gram/ & $50(50.0)$ \\
mg creatinine) & $50(50.0)$ \\
24 h urinary protein (abnormal >200 $\mathbf{~ m g )}$ & $26(26.0)$ \\
Lupus anticoagulant (LAC) antibodies & $33(33.0)$ \\
Anticardiolipin (ACL) antibodies & \\
\hline SLEDAl score & $2-22$ \\
\hline Range & $9.43 \pm 4.52$ \\
Mean $\pm S D$ & $14(14)$ \\
Mild (2-5) & $53(53)$ \\
Moderate (6-I I) & $33(33)$ \\
Severe ( $\geq I 2)$ &
\end{tabular}

Abbreviations: ESR, erythrocyte sedimentation rate; CRP, C-reactive protein; C3, Complement 3; C4, Complement 4; SLEDAI, systemic lupus erythematosus disease activity index.

helping in making an early diagnosis and in the specification of involved organs as well as initiation the appropriate treatment as early as possible. ${ }^{11}$

In this study, we aimed to estimate the frequency of ANA, anti-dsDNA, and anti-ENA antibodies among patients with JSLE and their association with the different clinical manifestations and the activity of the disease.

\section{Patients and Methods}

\section{Patients}

We conducted a cross-sectional study with 100 JSLE patients aged less than 18 years and were classified according to Systemic Lupus International Collaborating Clinics classification criteria. ${ }^{8}$ Patients were recruited from Ain Shams University Hospital from July 2019 to August 2020.

\section{Ethical Considerations}

We conducted this study according to the outlined principles of the World Medical Association's Declaration of Helsinki. Prior to the study, we explained the aim of the study and the involved procedures to the caregiver of the included patients; then, we obtained an informed consent from them. The ethics committee of Ain Shams University approved the protocol.

\section{Methods}

All the included participants underwent 1) A detailed history taking focusing on the following information: age, sex, disease duration. 2) A full clinical examination that includes rheumatological examination (clinical symptoms and manifestations were cumulative data). 3) Laboratory investigations (obtained at time of inclusion) were complete blood count, erythrocyte sedimentation rate, C-reactive protein, serum blood urea nitrogen, serum creatinine $(\mathrm{mg} / \mathrm{dL})$, creatinine clearance $(\mathrm{mL} /$ $\mathrm{min}$ ), complete urine analysis with assessment of active urinary sediments (RBCs - WBCs - proteins or cast), protein/creatinine ratio, $24 \mathrm{~h}$ urinary protein, serum complement (C3, C4), anticardiolipin (ACL) (IgG, IgM), and lupus anticoagulant (LAC). 4) Renal biopsy for patients with lupus nephritis (LN) (acute increase in serum

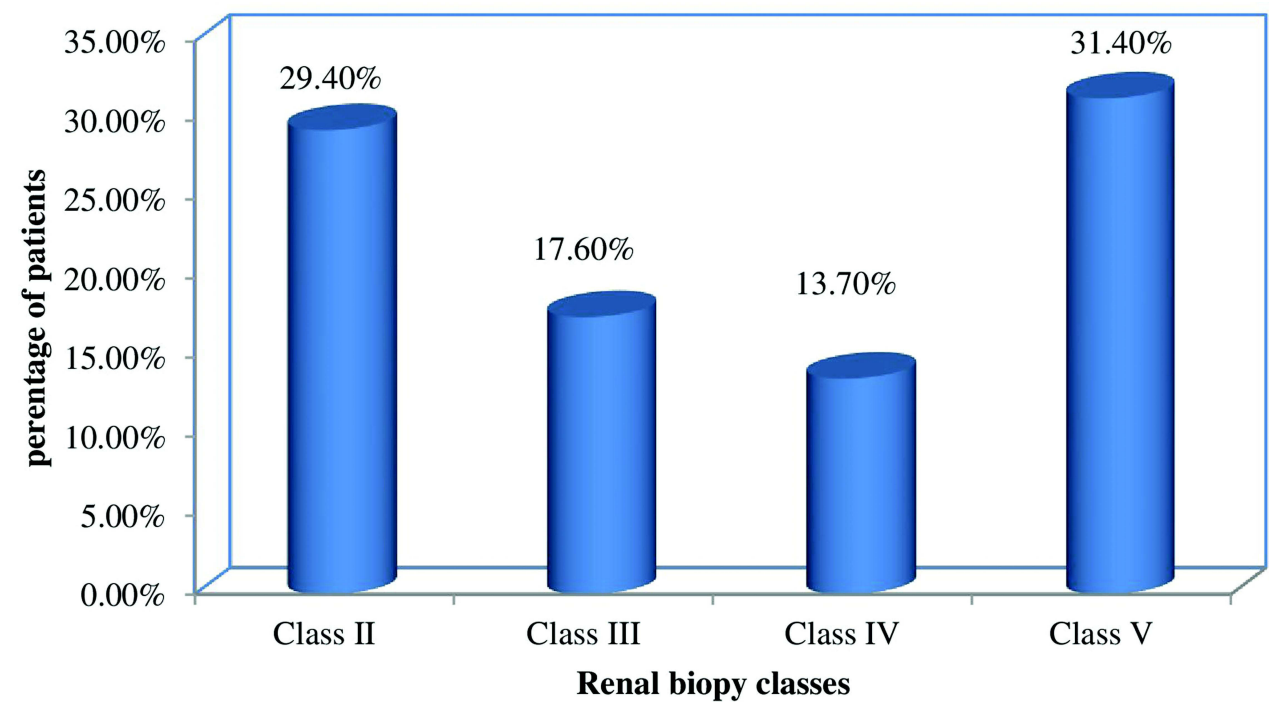

Figure I Distribution of renal biopsy classes among JSLE patients with lupus nephritis $(n=5 I)$. 
creatinine, proteinuria $>500 \mathrm{mg} / 24 \mathrm{~h}$ or urine protein/ creatinine ratio $>0.5 \mathrm{~g}$ protein $/ \mathrm{g}$ creatinine, hematuria in presence of any level of proteinuria, and active sediment/ cellular casts) with classification into six classes. ${ }^{12}$ 5) Indirect immunofluorescence (IF) assay in order to detect both ANA and anti-dsDNA antibodies. ${ }^{13}$ We considered a dilution of 1:160 positive in terms of detecting the ANA using the IF assay. Crithidia luciliae immunofluorescence test (CLIFT) was used for detection of Anti-DNA. For detecting the IgG autoantibodies formed against Sm, RNP, SSA, and SSB antigens, the blue DOT ENT IgG kit was used, which is based on the principle of enzyme immunoassay. $^{14}$

\section{Disease Activity Assessment}

We assessed the activity of the disease using the SLEDAI score, with the classification of patients as follows mild activity (SLEDAI $=2-5)$, moderate activity $($ SLEDAI $=6$ $11)$, high activity (SLEDAI $\geq 12) .{ }^{15}$ SLEDAI was obtained at the time of measuring of different autoantibodies.

\section{Statistical Analysis}

We analysed the recorded data using SPSS's statistical packages, version 20.0 (SPSS Inc., Chicago, IL, USA). We presented the quantitative data as mean \pm standard deviation (SD), while qualitative data were presented as frequencies and percentages. Multivariate logistic regression analysis, odds ratios (OR) with 95\% confidence intervals were computed to assess the overall association between each possible risk factor and the occurrence of autoantibodies. The adjusted ORs were estimated using a multivariate logistic regression model. Therefore, we considered the p-value as significant according to the following classification: 1) P-value $\leq 0.05$ : considered significant; 2) P-value $\leq 0.001$ : highly significant; and 3 ) $\mathrm{P}$-value $>0.05$ : insignificant.

\section{Results}

We included 100 JSLE subjects with a mean age of 12.91 \pm 1.94 years and disease duration of $3.57 \pm 2.66$ years. Females comprised the majority $(97 \%)$ of the patients, while only $3(3 \%)$ patients were male as presented in Table 1 . The frequency of different clinical and laboratory data among the studied patients is presented in Table 2; The most common clinical features were polyarthralgia (71\%), followed by haematological manifestations $(65 \%)$, malar rash (54\%), nephritis $(51 \%)$, photosensitivity $(47 \%)$, oral ulcer (33\%), alopecia (29\%), neuropsychiatric manifestations $(27 \%)$, cardiac involvement $(26.0 \%)$, thromboembolic event $(23 \%)$, serositis (12\%), and finally Raynaud's phenomena (8\%).

Using the distribution of renal biopsy classes (for patients with nephritis (51\%)); Class $\mathrm{V}$ was the most common class present in $16 / 51$ patients $(31.3 \%)$, class II in $15 / 51$ patients $(29.4 \%)$, class III in $9 / 51$ patients $(17.6 \%)$, and class IV was the last one in $7 / 51$ patients (13.7\%), as shown in Figure 1. Concerning SLEDAI score among JSLE patients, it was ranging from 2 to 22 with mean $9.43 \pm 4.52$, which was distributed as follows: 53 $(53 \%)$ patients with moderate disease activity, $33(33 \%)$ patients with severe disease activity, and only $12(12 \%)$ patients with mild disease activity.

Regarding frequency of drug therapy, hydroxychloroquine and corticosteroid were the most frequent used drugs $100(100 \%), 99(99.0 \%)$ of patients respectively followed by Mycophenolate mofetil 37 (37.0\%), cyclophosphamide 29 (29.0\%), azathioprine $18(18.0 \%)$ cyclosporine 4 $(4.0 \%)$, rituximab $2(2.0 \%)$, and finally Intravenous Immunoglobulin (IVIG) 4 (4.0\%)

With regard to the incidence of different autoantibodies; ANA and anti-dsDNA were the most frequent autoantibodies present (100\% and 83\%), respectively, followed by anti ENA (63\%), anti-RNP (41\%), anti-Sm (31\%), antiSSA/Ro (27\%), and anti-SSB/La (18\%) of patients (Figure 2). Frequency of anti-dsDNA and different antiENA antibodies profile in relation to different clinical manifestations and SLEDAI score in studied patients is presented in Table 3.

The significant association between different autoantibodies, variable clinical manifestations, laboratory data, and SLEADI score using multivariate regression analysis as shown in Table 4. Anti-dsDNA had a significant association with disease duration $(\mathrm{p}=0.011)$, consumed C3 $(\mathrm{p}=0.044)$, proteinuria $(\mathrm{p}<0.001)$, active urinary sediment $(p=0.046)$, LAC $(p=0.033)$ and was clinically associated with mucocutaneous, renal and hematological manifestations. SLEADI score was also significantly associated.

Regarding different anti-ENA antibodies, anti-RNP had a significant association with consumed $\mathrm{C} 3, \mathrm{C} 4$ $(\mathrm{p}=0.007, \quad \mathrm{p}=0.024), \quad$ proteinuria $\quad(\mathrm{p}=0.016), \quad \mathrm{ACL}$ $(p=0.043)$. Anti-RNP had a clinical association with oral ulcer, Raynaud' phenomena, haematological, neuropsychiatric and thromboembolic manifestations. Anti-Sm was associated with disease duration $(p=0.044)$, consumed C3 $(\mathrm{p}<0.001)$, proteinuria $(\mathrm{p}=0.015)$, active urinary sediment (pus cell $(\mathrm{p}=0.032)$, red cell $(\mathrm{p}=0.034)$, and urinary 


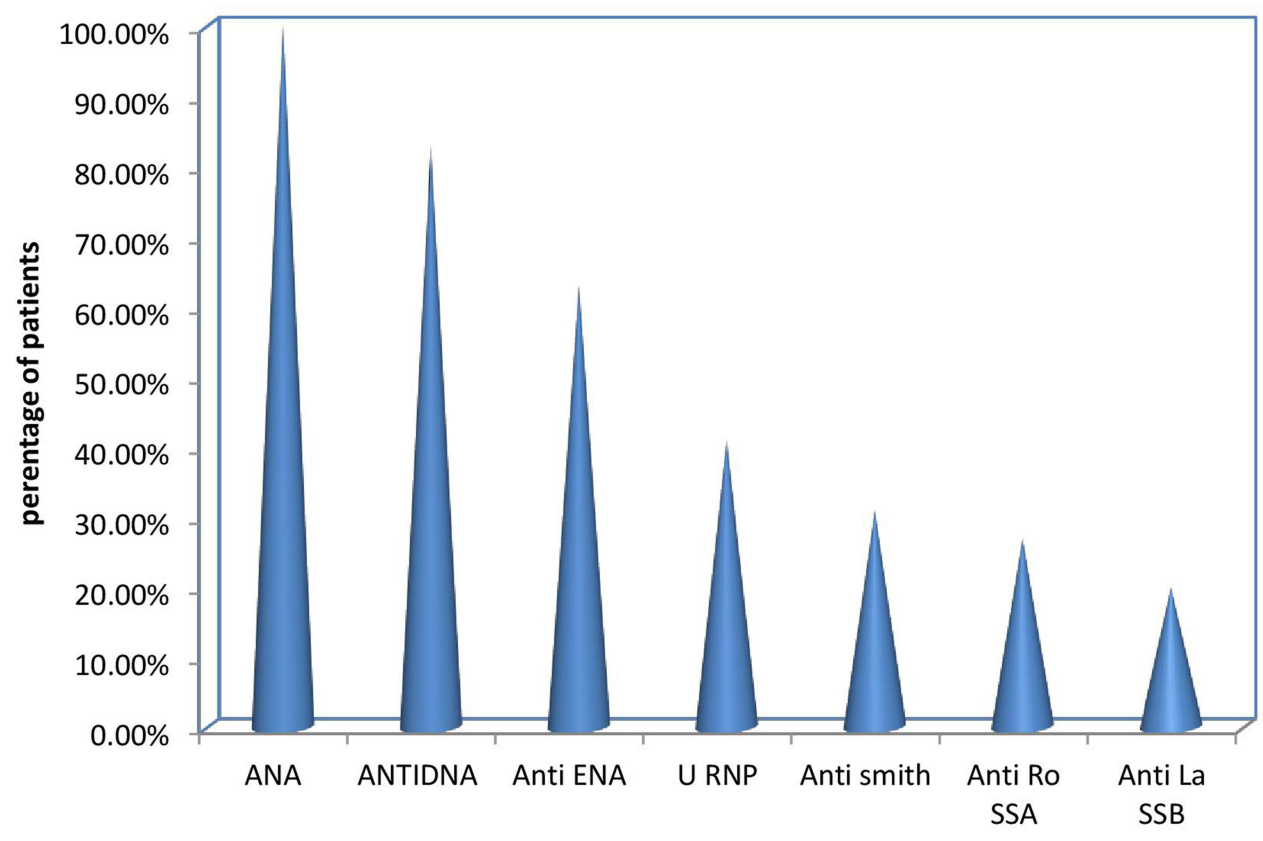

Autoantibodies

Figure 2 Distribution of anti-ENA and other autoantibodies found among JSLE patients. $(n=100)$.

cast $(p=0.010)$, ACL $(p=0.048)$. Meanwhile, for variable clinical manifestations, it had a significant association with serositis, mucocutaneous, constitutional, and neuropsychiatric manifestations. Anti-SSA was significantly associated with disease duration $(\mathrm{p}=0.044)$, consumed C3, C4 $(p=0.048, p=0.037)$, proteinuria $(p=0.049)$, and both of ACL, LAC $(p=0.043, p=0.038)$. It was associated with mucocutaneous, musculoskeletal, Raynaud' phenomena, renal, haematological and cardiac manifestations, while anti-SSB was associated with consumed C3 $(\mathrm{p}=0.020)$, proteinuria $(\mathrm{p}=0.039)$, and LAC $(\mathrm{p}<0.001)$ It was clinically related to malar rash, serositis, thromboembolic, musculoskeletal, and neuropsychiatric manifestations.

Different anti-ENA antibodies including (anti-SSA, antiSSB, anti-Sm, and anti-U1-RNP) were significantly associated with rising of SLEADI score (moderate and severe scores); anti-SSA/Ro was significantly associated with high disease activity $(p=0.045)$. Anti $\mathrm{SSB} / \mathrm{La}$ was significantly associated with both moderate and high disease activities $(p=p=0.002, p=0.004)$ respectively also the same for antiSm antibody $(p=0.029, p=0.018)$. Meanwhile anti-U1-RNP was associated with moderate disease activity $(\mathrm{p}=0.014)$.

\section{Discussion}

We conducted a cross-sectional study aiming to assess the frequency of ANA, anti-dsDNA, and ENA antibody profiles in JSLE patients. Associations of ENA profile with the clinical manifestations and disease activity score among JSLE patients were also observed in this cohort.

This study revealed that females were highly preponderance affected than males (97\% versus 3\%). Results of different studies, such as those by Ambrose et $\mathrm{al}^{16}$ and Balci et al, ${ }^{17}$ were similar to our results. The mean value of the age, at diagnosis, was $12.91 \pm 1.94$ years in our study. These results were not different from those demonstrated by Kini et al ${ }^{18}$ and Gomes et al. ${ }^{19}$

Musculoskeletal manifestation were the most prevalent clinical characteristics found in among those patients, in the form of polyarthralgia (71\%), followed by haematological manifestations (65\%), malar rash (54\%), nephritis (51\%), and neuropsychiatric manifestations (27\%). Similar results were obtained by different studies by Torrente-Segarra et al and Kosaraju et al who found that musculoskeletal manifestations were the most frequent clinical characteristics $(77.9 \%, 64.8 \%)$ respectively. ${ }^{20,21}$

The definitive diagnosis of $\mathrm{LN}$ is based on the immunofluorescence pattern on renal biopsy. In our study, Class $\mathrm{V}$ was the most common class $(16 \%)$ followed by class II $(15 \%)$. In an Indian study conducted by Srivastava et al, class III was the most common class $(46.7 \%) .{ }^{22}$ Meanwhile, the most common histopathological renal biopsy class was class IV (42.8\%) in the study by Andy and Kandasamy. ${ }^{23}$

We found that the SLEDAI score with a range of 2-22 with a mean of $9.43 \pm 4.52$. The Turkish and Canadian 


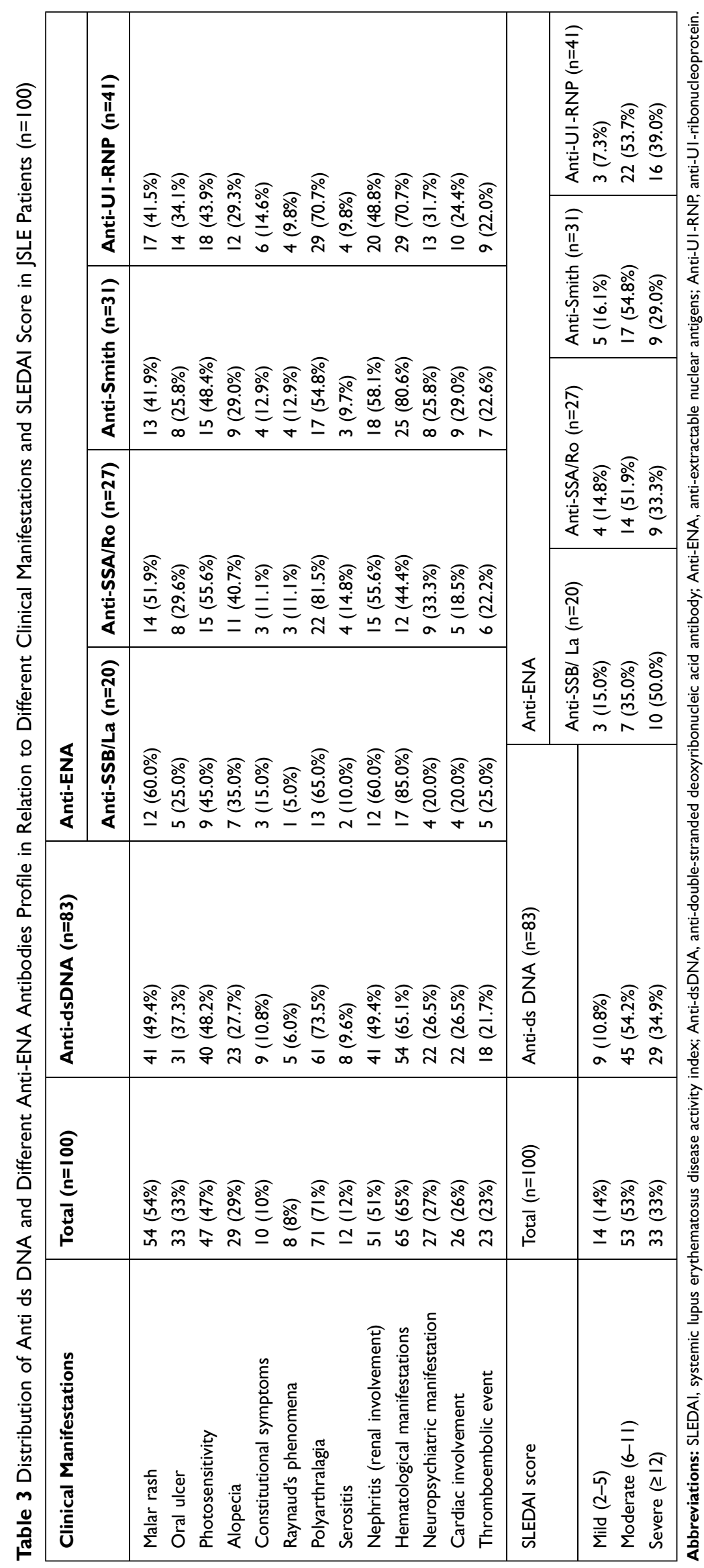


study conducted by Sahin et al and Hiraki et al showed similar results to our study results, ie, SLEDAI scores were $10.5 \pm 4.8$ and $13.1 \pm 8.4$, respectively. ${ }^{24,25}$ Higher disease activity scores were found in different studies such as those by Abdel-Hafez and Abdel-Nabi $(29.5 \pm 2.06)^{26}$ and Dung et al $(23.8 \pm 11.6){ }^{27}$

In this cohort study, the frequency of antiphospholipid antibodies among our patients were as follows: LAC antibodies in 26 patients (26.0\%), and ACL antibodies in 33 patients (33.0\%). Variable results were obtained from different studies; Balci et al found that anti-CL IgG and IgM were positivity seen in $8(15.1 \%)$ and 11 (20.8\%) patients, respectively, ${ }^{17}$ while Hiraki et al and Kim et al found that antiphospholipid antibodies were present in $32 \%$ and $42.8 \%$ of patients, respectively. ${ }^{25,28}$

Regarding autoantibody profiles, ANA was positive among all the patients (100\%), and results of other studies such as those by Dipti et al and Weiss, who found $100 \%$ and $99 \%$ ANA positivity, respectively, ${ }^{29,30}$ matched with our results, but ANA (IIF) was positive in $94 \%$ of SLE patients in the study by Gomes et al. ${ }^{19}$ Meanwhile, antidsDNA was detected in $83 \%$ of the samples in our study. Sahin et al found a similar result $(84.8 \%),{ }^{24}$ but a lower percentage was reported by Balci et al (45.3\%). ${ }^{17}$

A previous review showed that the anti-RNP and antiSm antibodies were detected among $25 \%-47 \%$ and $5-30 \%$ of SLE patients, respectively, in different studies while reviewing their ENA profile analysis. ${ }^{31}$

We found similar results, with anti-RNP (41\%) being the most common, followed by anti-Sm (31\%) and antiSSA $(27 \%)$, while anti-SSB was found in $20 \%$ of the patients. Among the ENA profiles, anti-RNP, anti-Sm, anti-SSA, and anti-SSB were positive in $36 \%, 31 \%$, $34 \%$, and $11 \%$, respectively, in a Brazilian study. ${ }^{32}$ Another study by Kadiyala et al reported similar results. ${ }^{33}$ Meanwhile, an Egyptian study found a much lower frequency of the U1-RNP antibodies $(10 \%){ }^{11}$

In our study, considering the correlation between autoantibodies and tissue involvement, we found that the antidsDNA antibodies have a significant association with mucocutaneous (malar rash, photosensitivity, oral ulcer, alopecia), renal and hematological manifestations. A study by Jurencak et al found that $\mathrm{LN}$ and malar rash with anti-dsDNA have a significant association. ${ }^{34}$ Moreover, Kadiyala et al found that dsDNA positivity was associated with $\mathrm{LN}(\mathrm{p}=0.04)$; however, it was not associated with other clinical manifestations. ${ }^{33}$
Anti-dsDNA also had a significant association with laboratory parameters of LN including consumed C3 $(p=0.044)$, proteinuria $(p<0.001)$, and active urinary sediment $(\mathrm{p}=0.046)$. Similar results were demonstrated in other studies. ${ }^{35,36}$

In this cohort study, anti-RNP was associated commonly with oral ulcer, Raynaud's phenomena, haematological, neuropsychiatric and thromboembolic manifestations Hoffman et al also demonstrated a significant association between anti-RNP and fever, malar rash, arthritis, and Raynaud's phenomenon in their study. ${ }^{37}$ Similar findings were demonstrated by another Brazilian study. ${ }^{38}$

Anti-RNP had a significant association with consumed $\mathrm{C} 3, \mathrm{C} 4(\mathrm{p}=0.007, \mathrm{p}=0.024)$, proteinuria $(\mathrm{p}=0.016)$ which indicate the association between anti-RNP and LN also it was associated with ACL $(p=0.043)$. Hiraki et al showed similar association. ${ }^{25}$

In the current study, anti-Sm was associated with serositis, mucocutaneous, constitutional, and neuropsychiatric manifestations. In an Afro-Caribbean cohort of SLE patients, rash, alopecia, mouth ulcers, serositis, neurological, joint and renal involvement were significantly associated with the presence of anti-Sm. ${ }^{39}$ Thompson et al also found that anti-Sm antibody has an association with both the malar rash and haematological and renal involvement among SLE patients. ${ }^{40}$ Meanwhile, Ahn et al found no association between LN and Anti-Sm. ${ }^{41}$

Anti-Sm was associated with consumed C3 $(\mathrm{p}<0.001)$, proteinuria $(\mathrm{p}=0.015)$, active urinary sediment (pus cell $(p=0.032)$, red cell $(p=0.034)$, and urinary cast $(p=0.010)$, which indicates a strong significant association between anti-Sm and severity of $\mathrm{LN}$ and with disease duration $(p=0.044)$. Emad et al also found similar findings. ${ }^{11}$ A Korean study reported that anti-Sm identified at kidney biopsy was suggested to have a predictive value for the early poor outcome of biopsy-proven LN during the follow-up period. ${ }^{42}$ In contrast to our results, Tapanes et al found that SLE patients with anti-Sm antibodies had a lower prevalence of urine cellular casts. ${ }^{43}$

Anti-SSA was significantly associated with mucocutaneous, musculoskeletal, Raynaud' phenomena, renal, haematological, cardiac manifestations. Swedish study demonstrated Anti-SSA was only associated with mucocutaneous manifestation but not with arthritis, ${ }^{44}$ while Li et al reported a positive association between anti-SSA and both mucocutaneous manifestation and arthritis. ${ }^{45}$

Laboratory parameters of LN (consumed C3, C4 $(\mathrm{p}=0.048, \mathrm{p}=0.037)$, proteinuria $(\mathrm{p}=0.049))$, and both of ACL, LAC antibodies $(\mathrm{p}=0.043, \quad \mathrm{p}=0.038)$ were 


\begin{tabular}{|c|c|c|c|c|c|c|c|c|c|c|c|c|c|c|c|c|c|c|}
\hline & 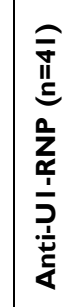 & 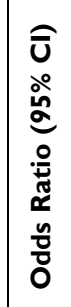 & & 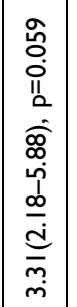 & 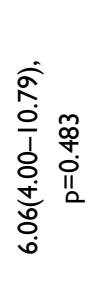 & 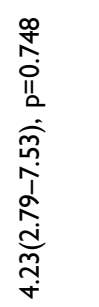 & & 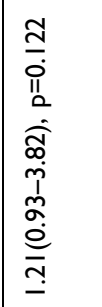 & 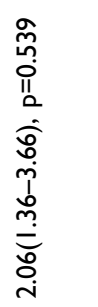 & & 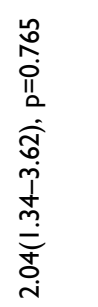 & 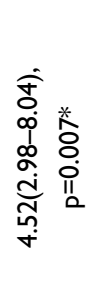 & & 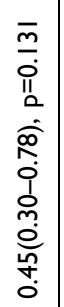 & 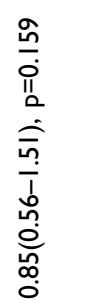 & 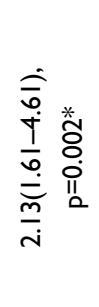 & 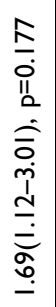 & 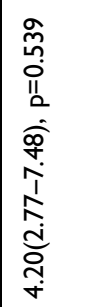 \\
\hline z & 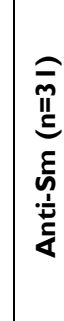 & 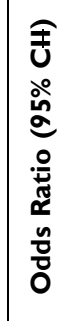 & & 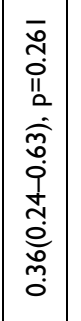 & 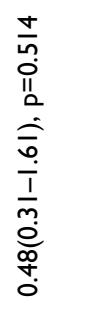 & 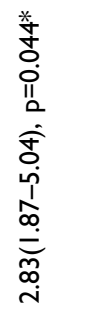 & & 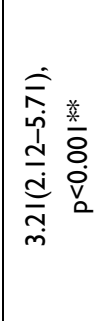 & 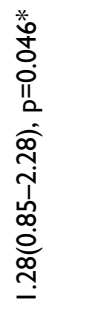 & & 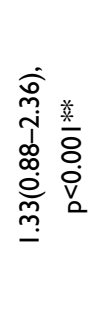 & 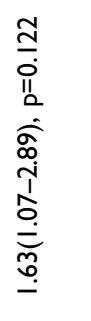 & & 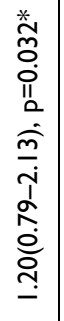 & 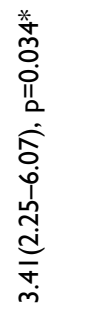 & 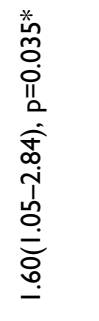 & 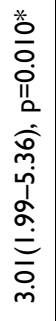 & 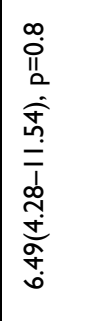 \\
\hline 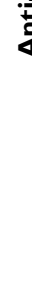 & 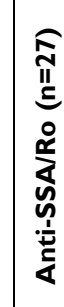 & 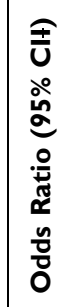 & & 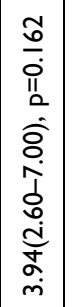 & 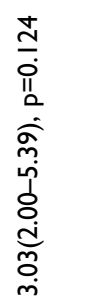 & 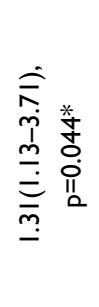 & & 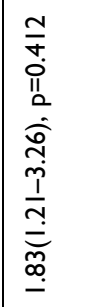 & 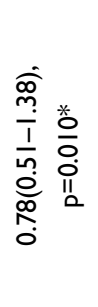 & & 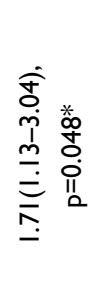 & 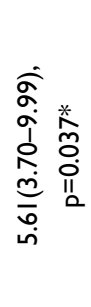 & & 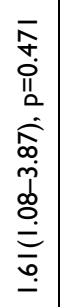 & 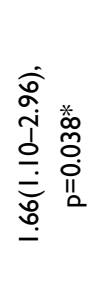 & 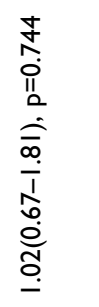 & 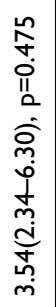 & 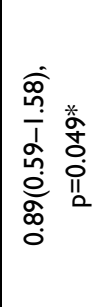 \\
\hline & 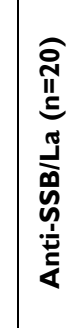 & 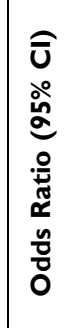 & & 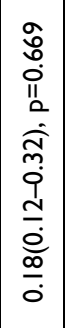 & 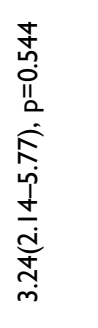 & 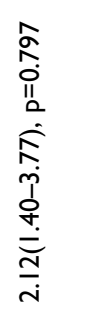 & & 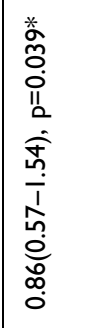 & 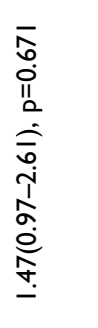 & & 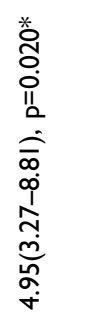 & 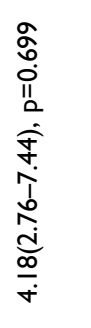 & & 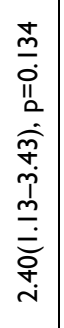 & 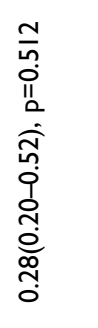 & 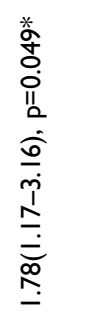 & 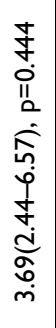 & 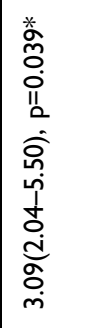 \\
\hline 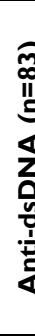 & & 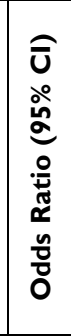 & & 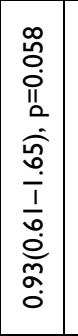 & 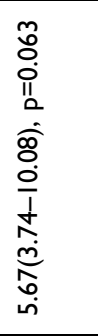 & 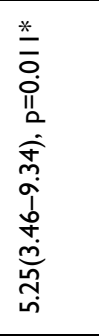 & & 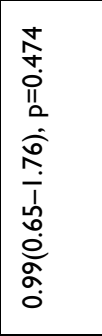 & 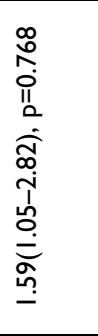 & & 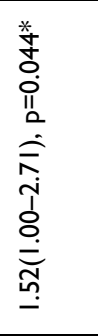 & 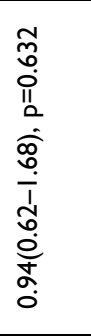 & & 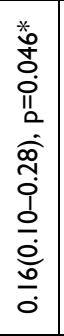 & 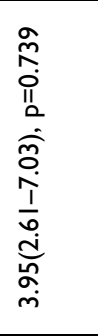 & 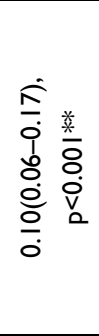 & 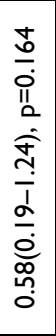 & 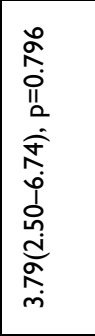 \\
\hline 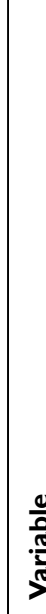 & 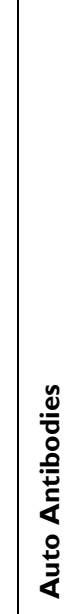 & & 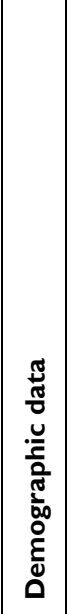 & 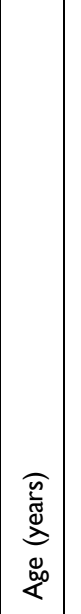 & œ & 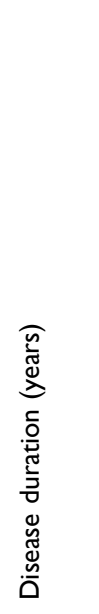 & 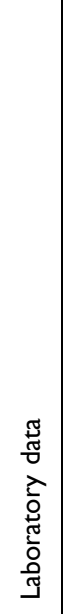 & 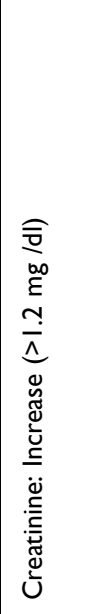 & 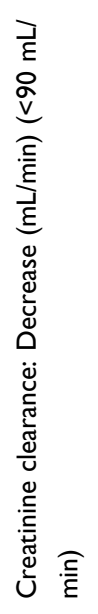 & 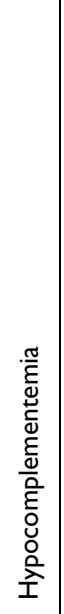 & 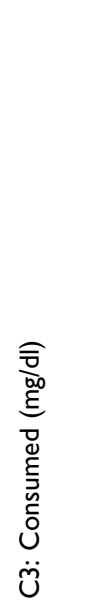 & 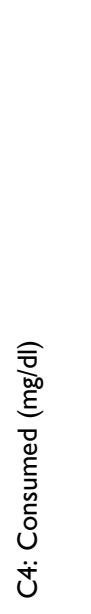 & 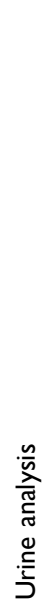 & $\begin{array}{l}\overline{\bar{U}} \\
\underline{y} \\
0\end{array}$ & $\begin{array}{l}\overline{\bar{Q}} \\
\stackrel{\mathcal{Q}}{\mathscr{Q}} \\
\propto\end{array}$ & 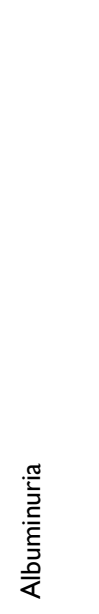 & 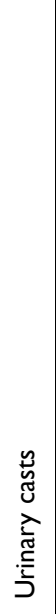 & 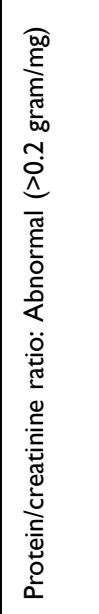 \\
\hline
\end{tabular}




\begin{tabular}{|c|c|c|c|c|c|c|c|c|c|c|c|c|c|c|c|}
\hline 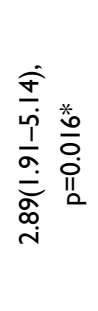 & 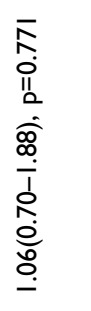 & 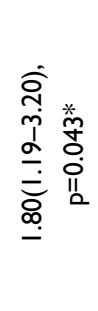 & & 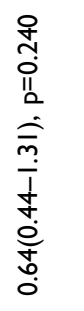 & 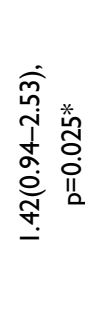 & 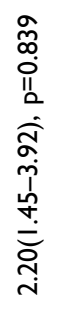 & 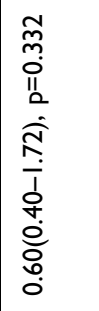 & 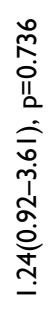 & 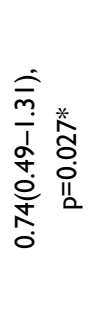 & 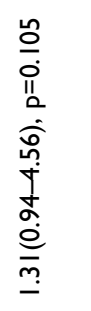 & 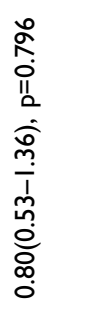 & 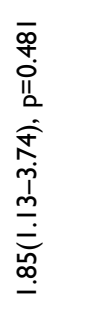 & 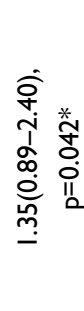 & 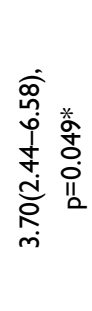 & 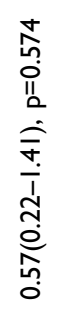 \\
\hline 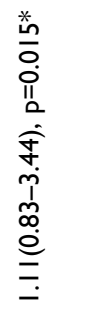 & 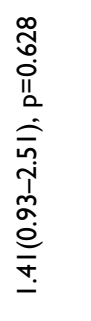 & 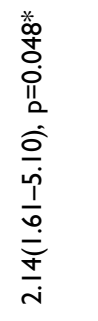 & & 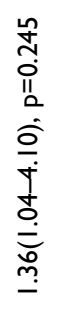 & 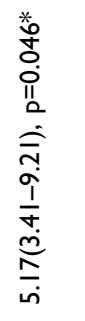 & 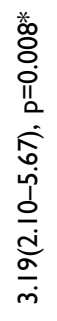 & 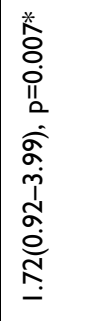 & 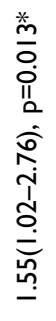 & 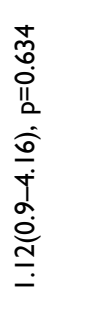 & 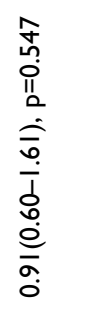 & 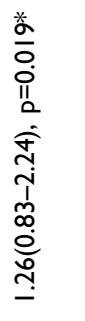 & 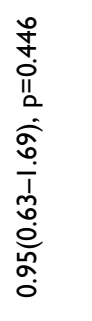 & 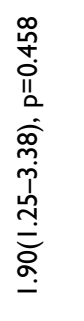 & 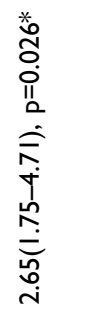 & 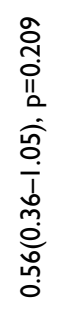 \\
\hline 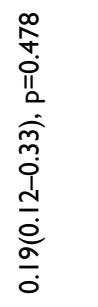 & 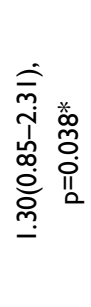 & 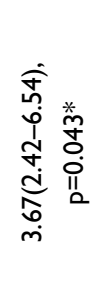 & & 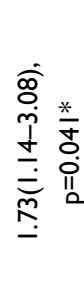 & 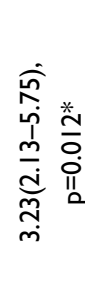 & 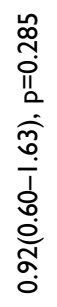 & 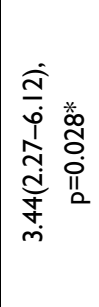 & 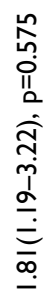 & 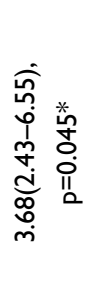 & 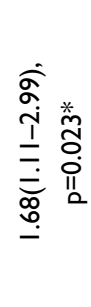 & 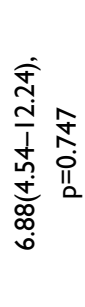 & 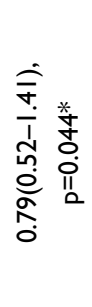 & 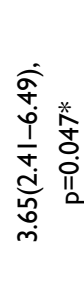 & 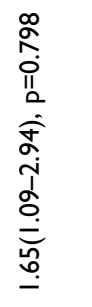 & $\begin{array}{l}\hat{f} \\
\hat{j} \\
\hat{p}\end{array}$ \\
\hline 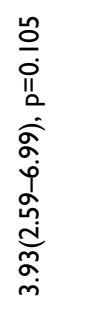 & 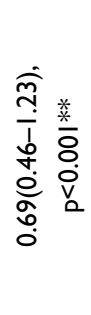 & 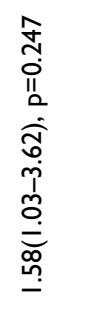 & & 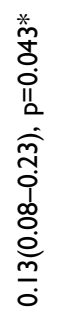 & 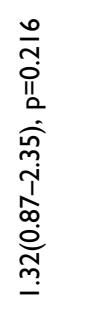 & 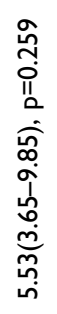 & 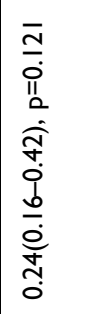 & 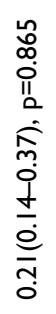 & 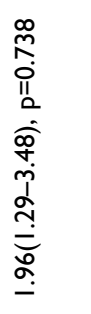 & 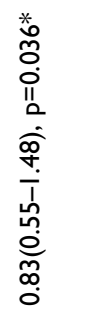 & 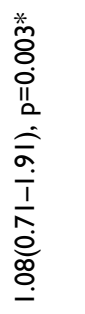 & 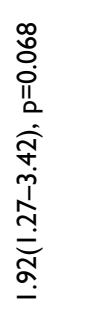 & 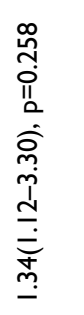 & 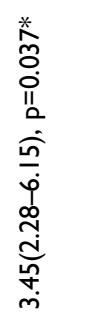 & 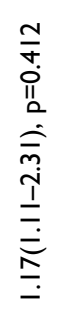 \\
\hline 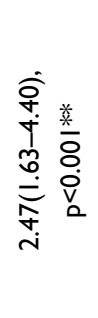 & 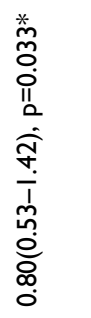 & 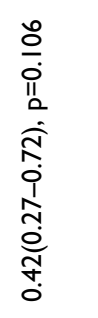 & & 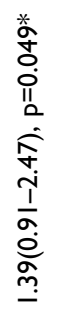 & 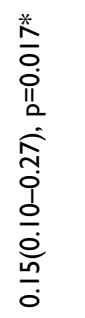 & 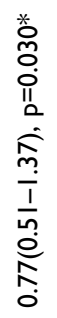 & 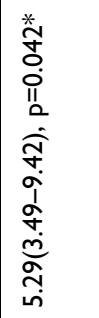 & 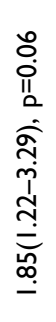 & 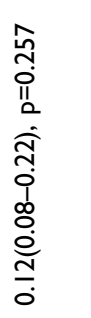 & 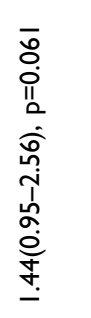 & 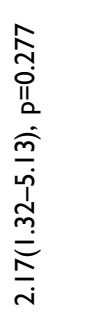 & 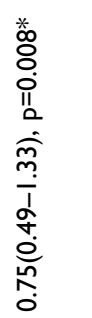 & 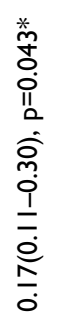 & 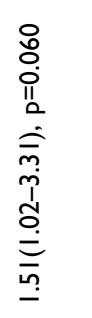 & 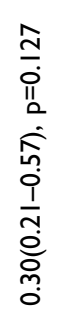 \\
\hline 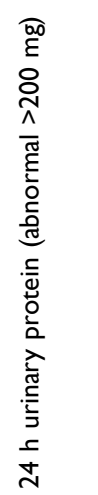 & 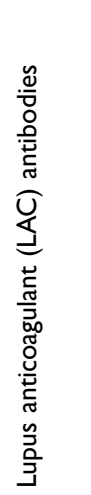 & 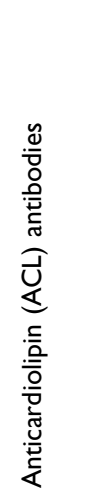 & $\begin{array}{l}\frac{\pi}{\pi} \\
\frac{\pi}{0} \\
\frac{\pi}{\pi} \\
\frac{\pi}{U}\end{array}$ & 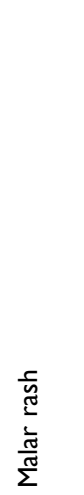 & 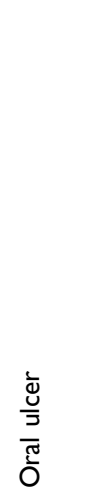 & 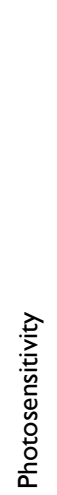 & $\begin{array}{l}\frac{\pi}{\tilde{U}} \\
\frac{0}{\alpha} \\
\frac{0}{\alpha}\end{array}$ & 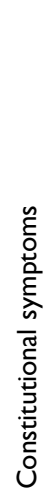 & 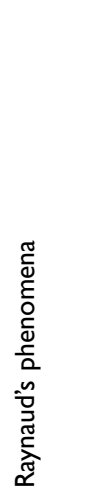 & 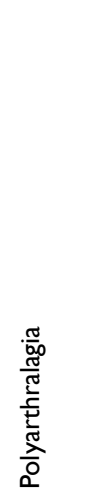 & 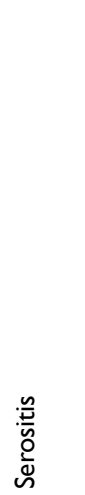 & 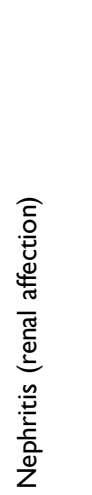 & 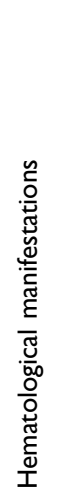 & 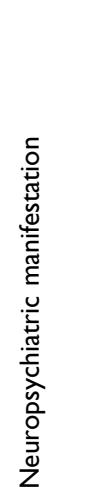 & 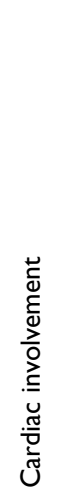 \\
\hline
\end{tabular}


significantly associated with anti-SSA antibodies. Emad et al found significant correlation between anti-SSA and consumed $\mathrm{C} 3$ but not correlated to other laboratory data. ${ }^{11}$ The reason for the contradictory findings may be sought in differences in methodology as well as in genetic factors.

Anti-SSB antibody was clinically related to malar rash, serositis, thromboembolic, musculoskeletal, and neuropsychiatric manifestations. Rao et al found that anti-SSB antibody was identified to be associated with cheek erythema, alopecia, serositis and neurological manifestations. The mechanism behind this is unknown and may be related to the deposition or formation of a local antigen-antibody complex, which causes local vascular inflammation, increased vascular permeability, or microcirculatory disturbance. ${ }^{46}$ It was also significantly associated with consumed $\mathrm{C} 3(\mathrm{p}=0.020)$, proteinuria $(p=0.039)$, and LAC $(p<0.001)$. Emad et al found a significant correlation with $\mathrm{C} 3(\mathrm{p}$ value $=0.004),{ }^{11}$ while Hiraki et al correlated them to LAC antibodies. ${ }^{25}$

In the opposite of our study, Kini et al observed that the different anti-ENA antibodies and the characteristic organ involvement did not have any association. ${ }^{18}$ This difference in results may be attributed to the different ethnic backgrounds, geographical locations, age, and number of the study population.

In this cohort, different anti-ENA antibodies including (anti-SSA, anti-SSB, anti-Sm, and anti-U1-RNP) were significantly associated with rising of SLEADI score; thus, autoantibodies have a positive association with the severity of the disease. These findings may be explained by a significant association between consumed complement (critical pathway in the pathogenesis of SLE), active urinary sediment and proteinuria which are parameters of disease activity with different anti-ENA antibodies.

Similar results were obtained from different studies, as Emad et al who stated that the score of the disease activity was significantly correlated with the different anti-ENA antibodies as anti-Sm, anti-SSA, and antiSSB. However, it was not significantly correlated with anti-U1-RNP ${ }^{11}$ Ahn et al stated that the anti-Sm antibody and the activity of the disease were significantly correlated. ${ }^{41}$ In contrast, Agarwal et al found that there was no association between different anti-ENA antibodies and disease activity score. ${ }^{47}$

Our study had some limitations; it was a cross-sectional study, all of the patients held a unique Egyptian background, and study was conducted at certain point of time, so we cannot say, whether the association will persist over time 
and during transitional zone from juvenile to adulthood period. We encouraged further longitudinal studies in different geographical regions and ethnic populations could help to identify the role that autoantibodies play in SLE.

\section{Conclusion}

Anti-dsDNA and anti-ENA antibodies were frequently found in JSLE patients $(83 \%, 63 \%)$ respectively. They were significantly associated with variable clinical manifestations and could be used as predictors for assessment of disease activity. These antibodies may lead to new approaches to diagnostic testing, accurate evaluation of disease activity, and forecast different clinical manifestations early in the disease course. The early identification for the involvement of the organs and the initiation of the appropriate management as early as possible could potentially and will eventually decrease the morbidity and mortality among those patients.

\section{Acknowledgments}

We would like to thank all our subjects, as well as the supervisors and authors who contributed in this work.

\section{Funding}

We declare that this research did not receive any grants from any funding institution, either its public, commercial or not-for-profit sector.

\section{Disclosure}

We declare no conflicts of interest with respect to the research, authorship, and/or publication of this article.

\section{References}

1. Wang F, Zhang W, Wang S, et al. Protective effects of antimalarial in Chinese patients with systemic lupus erythematous. Ann Rhum Dis. 2018;78-e80. doi:10.1136/annrheumdis-2018-213819

2. Groot N, De Graeff N, Avcin T, et al. European evidence-based recommendations for diagnosis and treatment of childhood-onset systemic lupus erythematosus. The SHARE initiative. Ann Rheum Dis. 2017;76:1788-1796. doi:10.1136/annrheumdis-2016-210960

3. Nalbanti P, Stefanidou S, Alfantaki S, et al. A 5-year multicenter comparative study between patients with juvenile and adult-onset systemic lupus erythematosus. Pediatriki. 2012;72-85. Greek.

4. Zharkova O, Celhar T, Cravens PD, Satterthwaite AB, Fairhurst AM. Davis LS. Pathways leading to an immunological disease: systemic lupus erythematosus. Rheumatology (Oxford). 2017;56(1):i55-i66. doi:10.1093/rheumatology/kew427

5. Phan TG, Wong RC. Adelstein S Autoantibodies to extractable nuclear antigens: making detection and interpretation more meaningful. Clin Diagn Lab Immunol. 2002;9(1):1-7.

6. Sallai K, Nagy E, Derfalvy B, Müzes G, Gergely P. Antinucleosome antibodies and decreased deoxyribonuclease activity in sera of patients with systemic lupus erythematosus. Clin Diagn Lab Immunol. 2005;12:56-59.
7. Hochberg MC. Updating the American College of Rheumatology revised criteria for the classification of systemic lupus erythematosus. Arthritis Rheum. 1997;40(9):1725. doi:10.1002/ art.1780400928

8. Petri M, Orabi A, Alarcón GS, et al. Derivation and validation of the systemic lupus international collaborating clinics classification criteria for systemic lupus erythematosus. Arthritis Rheum. 2012;64:2677-2686. doi:10.1002/art.34473

9. Rekvig OP. The anti-DNA antibody: origin and impact, dogmas and controversies. Nat Rev Rheumatol. 2015;11(9):530-540. doi:10.1038/ nrrheum.2015.69

10. Linnik MD, Hu JZ, Heilbrunn KR, Strand V, Hurley FL. Relationship between anti-double-stranded DNA antibodies and exacerbation of renal disease in patients with systemic lupus erythematosus. Arthritis Rheum. 2005;52(4):1129-1137. doi:10.1002/art.20980

11. Emad Y, Gheita T, Darweesh H, et al. Antibodies to extractable nuclear antigens (ENAS) in systemic lupus erythematosus patients: correlations with clinical manifestations and disease activity. Reumatismo. 2018;70:85-91. doi:10.4081/reumatismo.2018.1027

12. Weening JJ, D'Agati VD, Schwartz MM, et al. The classification of glomerulonephritis in systemic lupus erythematosus revisited. Kidney Int. 2004;65:521-530. doi:10.1111/j.1523-1755.2004.00443.x

13. Von Mühlen CA, Tan EM. Autoantibodies in the diagnosis of systemic lupus erythematosus. Semin Arthritis Rheum. 1995;5:323-358.

14. Emlen W, O'Neil L. Clinical significance and interpretation of anti-nuclear antibodies: comparison of detection with immunofluorescence and enzyme linked immunosorbent assays. Arthris Rheum. 1997;40:1612-1618. doi:10.1002/art.1780400910

15. Gladman DD, Ibañez D, Urowitz MB. Systemic lupus erythematosus disease activity index 2000. $J$ Rheumatol. 2002;29:288-291.

16. Ambrose N, Morgan TA, Galloway J, Ionnoau Y, Beresford MW, Isenberget DA. Differences in disease phenotype and severity in SLE across age groups. Lupus. 2016;25:1542-1550. doi:10.1177/ 0961203316644333

17. Balci S, Ekinci RMK, Bayazit AK, et al. Juvenile systemic lupus erythematosus: a single-center experience from southern Turkey. Clin Rheumatol. 2019;38:1459-1468. doi:10.1007/s10067-019-04433-4

18. Kini S, Bhat RY, Thunga C, et al. Clinical and immunological spectrum of systemic lupus erythematosus in children. $J$ Nepal Paediatr Soc. 2020;40:14-20. doi:10.3126/jnps.v40i1.28460

19. Gomes KB, Islam MI, Rahman S. Autoantibody profile and its association with clinical presentation of pediatric SLE patients. Am J Pediatr. 2019;5:178-182. doi:10.11648/j.ajp.20190504.11

20. Torrente-Segarraa V, Salman-Monteb TC, Figueroac IR. Associated factors to serious infections in a large cohort of juvenile-onset systemic lupus erythematosus from Lupus Registry (RELESSER). Semin Arthritis Rheum. 2020;50:657-662. doi:10.1016/j.semarthrit.2020.05.016

21. Kosaraju K, Shenoy S, Suchithra UA. Cross-sectional hospital based study of autoantibody profile and clinical manifestations in south Indian patients. Indian J Med Microbiol. 2010;28:245-247.

22. Srivastava P, Abujam B, Misra R, Lawrence A, Agarwal V, Aggarwal A. Outcome of lupus nephritis in childhood onset SLE in North and Central India!: single-centre experience over 25 years. Lupus. 2015;1:1-11.

23. Andy SK, Kandasamy E. Clinical profile of systemic lupus erythematosus among children less than 12 years. Int J Contemp Pediatr. 2018;5:343-349. doi:10.18203/2349-3291.ijcp20180458

24. Sahin S, Adrovic A, Barut K, et al. Juvenile systemic lupus erythematosus in Turkey: demographic, clinical and laboratory features with disease activity and outcome. Lupus. 2018;27:514-519. doi:10.1177/0961203317747717

25. Hiraki LT, Benseler SM, Tyrrell PN, Hebert D, Harvey E, Silverman ED. Clinical and laboratory characteristics and long term outcome of pediatric systemic lupus erythematosus: a longitudinal study. $J \quad$ Pediatr. 2008;152:550-556. doi:10.1016/j. jpeds.2007.09.019. 
26. Abdel-Hafez MA, Abdel-Nabi H. Juvenile systemic lupus erythematosus: onset patterns and short-term outcome in Egyptian children, a single-center experience. Lupus. 2015;24:1455-1461. doi:10.1177/ 0961203315598016

27. Dung NT, Loan HT, Nielsen S, Zak M, Petersen FK. Juvenile systemic lupus erythematosus onset patterns in Vietnamese children: a descriptive study of 45 children. Pediatr Rheumatol Online J. 2012;10:38. doi:10.1186/1546-0096-10-38

28. Kim H, Levy DM, Silverman ED, et al. A comparison between childhood and adult onset systemic lupus erythematosus adjusted for ethnicity from the 1000 Canadian Faces of Lupus Cohort. Rheumatology. 2019;58:1393-1399. doi:10.1093/rheumatology/ kez006

29. Dipti TR, Azam MS, Sattar MH, Rahman SA. Detection of antinuclear antibody in childhood rheumatic diseases by immunofluorescence assay and enzyme immunoassay. Bangladesh $J$ Child Health. 2011;35:49-52. doi:10.3329/bjch.v35i2.10355

30. Weiss JE. Pediatric systemic lupus erythematosus: more than a positive antinuclear antibody. Pediatr Rev. 2012;33:62-74. doi:10.1542/pir.33-2-62

31. Migliorini P, Baldini C, Rocci V, Bombardieri S. Anti-Sm and anti-RNP antibodies. Autoimmunity. 2005;38:47-54. doi:10.1080/ 08916930400022715

32. Liphus BL, Kiss MHB, Goldberg AC. HLA -DRB1 alleles in juvenile onset systemic lupus erythematosus: renal histologic class correlations. Braz J Med Biol Res. 2007;40:591-597. doi:10.1590/S0100879X2007000400019

33. Kadiyala R, Kini PG, Aroor S, Kumar S, Moras K. Clinicoimmunological profile and outcome of childhood systemic lupus Erythematosus. Sri Lanka J Child Health. 2019;48:201-207. doi:10.4038/sljch.v48i3.8753

34. Jurencák R, Fritzler M, Tyrrell P, Hiraki L, Benseler S, Silverman E. Autoantibodies in pediatric systemic lupus erythematosus! Ethnic grouping, cluster analysis, and clinical correlations. J Rheumatol. 2009;36:416-421. doi:10.3899/jrheum.080588

35. Sherer Y, Gorstein A, Fritzler MJ, Shoenfeld Y. Autoantibody explosion in systemic lupus erythematosus: more than 100 different antibodies found in SLE patients. Semin Arthritis Rheum. 2004;34 (2):501-537.

36. Cortes-Hernandez J, Ordi-Ros J, Labrador M, et al. Antihistone and anti-double-stranded deoxyribonucleic acid antibodies are associated with renal disease in systemic lupus erythematosus. Am J Med. 2004;116(3):165-173. doi:10.1016/j.amjmed.2003.08.034
37. Hoffman IEA, Peene I, Meheus L, et al. Specific antinuclear antibodies are associated with clinical features in systemic lupus erythematosus. Ann Rheum Dis. 2004;63:1155-1158. doi:10.1136/ ard.2003.013417

38. Marina M, Melissa FE, Paulo HRN, Thelma LS. Anti RNP in systemic lupus erythematosus. Acta Reumatol Port. 2013;38:136-137.

39. Morasis SA, Isenberg DA. A study of the influence of ethnicity on serology and clinical features in lupus. Lupus. 2017;26:17-26. doi:10.1177/0961203316645204

40. Thompson D, Juby A, Davis P. The clinical significance of autoantibody profiles in patients with systemic lupus erythematosus. Lupus. 1993;2:15-19. doi:10.1177/096120339300200104

41. Ahn SS, Min JS, Yoo J, Lee SW, Song JJ, Park YB. Anti-Smith antibody is associated with disease activity in patients with new-onset systemic lupus erythematosus. Rheumatol Int. 2019;39:1937-1944. doi:10.1007/s00296-019-04445-y

42. Ahn SS, Yoo BW, Song JJ, Park YB, Lee SK, Lee SW. Anti-Sm is associated with the early poor outcome of lupus nephritis. Int J Rheum Dis. 2016;19:897-902. doi:10.1111/1756-185X.12880

43. Tapanes FJ, Vasquez M, Ramirez R, et al. Cluster analysis of antinuclear autoantibodies in the prognosis of SLE nephropathy: are anti-extractable nuclear antibodies protective? Lupus. 2000;9:437-444. doi:10.1191/096120300678828604

44. Frodlund M, Dahlstrom O, Kastbom A, Skogh T, Sjowall C. Association between antinuclear antibody staining patterns and clinical features of systemic lupus erythematosus: analysis of a regional Swedish register. BMJ Open. 2013;3:10. doi:10.1136/bmjopen-2013003608

45. Li PH, Wong WH, Lee TL, et al. Relationship between autoantibody clustering and clinical subsets in SLE: cluster and association analyses in Hong Kong Chinese. Rheumatology (Oxford). 2013;52:337-345. doi:10.1093/rheumatology/kes261

46. Rao L, Liu G, Li C, et al. Specificity of anti-SSB as a diagnostic marker for the classification of systemic lupus erythematosus. Exp Ther Med. 2013;5(6):1710-1714. doi:10.3892/etm.2013.1051

47. Agarwal S, Harper J, Kiely PD. Concentration of antibodies to extractable nuclear antigens and disease activity in systemic lupus erythematosus. Lupus. 2009;18:407-412. doi:10.1177/ 0961203308097784
Open Access Rheumatology: Research and Reviews

\section{Publish your work in this journal}

Open Access Rheumatology Research and Reviews is an international, peer-reviewed, open access journal publishing original research, reports, editorials, reviews and commentaries on all aspects of clinical and experimental rheumatology in the clinic and laboratory including the following topics: Pathology, pathophysiology of rheumatological diseases; Investigation, treatment and management of rheumatological diseases; Clinical trials and novel pharmacological approaches for the treatment of rheumatological disorders. The manuscript management system is completely online and includes a very quick and fair peer-review system, which is all easy to use. Visit http://www.dovepress.com/testimonials.php to read real quotes from published authors. 